\title{
CHARACTERIZING VIRTUAL ORGANIZATIONS AND THEIR MANAGEMENT
}

\author{
Iris Karvonen, Iiro Salkari, Martin Ollus \\ VTT Industrial Systems \\ Iris.Karvonen@vtt.fi liro.Salkari@vtt.fi Martin.Ollus@vtt.fi \\ FINLAND
}

\begin{abstract}
Virtual Organization (VO) Management aims to the achievement of the objectives of the VO. It can be seen as a set of mechanisms and activities directing and controlling $V O$ operation. As different VOs have different objectives and environment, different approaches for VO management are needed. The paper discusses the concept of VO management and presents an outline for building VO management approaches based on VO characteristics or descriptive parameters. First analysis of practical cases against the characteristics has been performed. Further development is needed to specify the management methods and mechanisms for different approaches.
\end{abstract}

\section{INTRODUCTION}

The research in the area of Collaborative Networked Organizations (CNO) has been active during the last years. Especially information and communication technology solutions and infrastructure have been developed. VOSTER (VOSTER 2004) has analysed and structured some results and experiences of this research. In this paper, the term "virtual organization" is understood as it is defined by VOSTER (Kürümlüoglu et al., 2005): "Virtual organisation (VO) is a temporary consortium of partners from different organisations established to fulfil a value adding task, for example a product or service to a customer." Effective operation in VOs requires preparedness, which can be achieved by a long-term co-operation in the so called Breeding Environment (BE) (or Network).

This paper focuses on the VO management and discusses the configuration of the VO management for different circumstances. The concept of VO management is defined, and the supporting previous knowledge is briefly reviewed. As Virtual Organizations (VOs) respond to specific business opportunities, the VO management mechanism also needs to adopt to the cases. The paper aims to identify the main features affecting VO management and to define VO management approaches. This could support the end-users in the definition of cost-effective and dependable VO structures, management structures and mechanisms. 


\section{VO MANAGEMENT}

\subsection{Definition}

The Virtual Organization Management (VOM) denotes the organization, allocation and co-ordination of resources and their activities as well as their interorganisational dependencies to achieve the objectives of the VO within the required time, cost and quality frame.

The VOM applies knowledge, skills and/or tools in order to achieve the VO goals. Obviously, the management of Virtual Organizations to a large extent deals with humans and is performed by humans. In most cases the human aspect is considerable as the last decisions about management actions usually are done by the VO managers.

At a high level description, VOM can be seen as the management and control of the VO lifecycle. More detailed, VOM can be seen as a separate process interacting with the VO operational processes. VOM receives data and information of the status of the VO operation. Actions are based on the comparison of actual achieved behaviour compared to the wanted behaviour. They are supposed to be proactive in order to avoid also emerging deviations from the expected outcome.

Figure 1 expands the control loop view. In addition to the real-time VOM process (control loop), VOM includes mechanisms and rules, which influence the VO operation and can be seen as part of VOM. Most of these rules have to be developed in advance, typically in the VBE (Virtual Breeding Environment) behind.

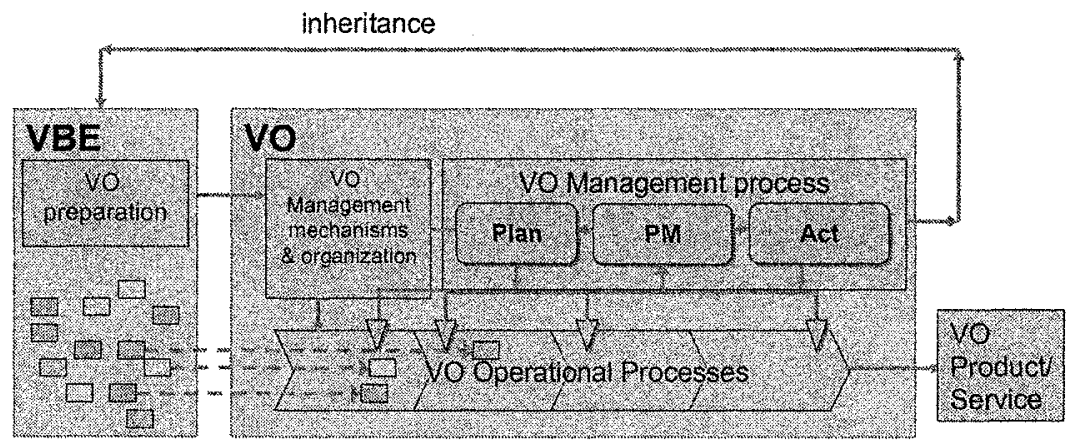

Figure 1. VOM

\subsection{Views to Virtual Organisations Management}

The VOM has to be based on the models of the processes to be managed. In order to get a comprehensive coverage, a structuring of the modelling views is needed. The structuring can be based on the views of model content defined in GERAM and also used as a basis in VERAM (GERAM, 1999):

1. Function View represents the functionalities (activities) and the behavior (flow of control) of the business processes of the VO. The function view includes functional models, process models and decisional models. 
2. Information View collects the knowledge about objects of the VO needed for the management tasks.

3. Resource View represents the resources of the VO. Resources are assigned to activities according to their capabilities and are structured into resource models for VOM tasks

4. Organisation View represents the responsibilities and authorities on all entities identified in the other views.

In the implementation of a VOM these views need to be considered, but also other aspects like the division between human activities and activities performed by the system may have to be addressed.

\subsection{Virtual Organisations and Project Management}

Projects, as they are performed e.g. in the capital intensive production, have several similarities to Virtual Organisations. Project management can be considered as one basis for the development of management approaches for VOs. The Project Management Body of Knowledge (PMBOK) developed by Project Management Institute Standards Committee describes the generally accepted knowledge of projects.

The PMBOK (1996) defines that "a project is a temporary endeavour undertaken to create a unique product or service". The impermanence and a specific objective is common with the definition of a VO, but the inter-organizational precondition and preparation is missing. A dynamic VO is an outcome of a deeper preparatory cooperation between partners than a project, which is based on loosely defined principles, implemented to some extend ad-hoc, since no long-term preparatory cooperation exists. In the VO concept, proactive cooperation takes place in the VBE (Camarinha-Matos and Afsarmanesh, 2003).

According to $\mathrm{PMBOK}$, project management consists of integration, scope, time, cost, quality, human resource, communications, risk, and procurement management. Further, PMBOK (p. 28) organises project management processes into five groups:

- Initiating processes, which recognise that a project or phase should begin

- Planning processes, which devise and maintain workable scheme to accomplish the business need that the project was undertaken to address

- Executing processes, which coordinate people and other resources to carry out the plan

- Controlling processes, which ensure that project objectives are met by monitoring and measuring progress and taking corrective action when necessary

- Closing processes, which formalize acceptance of the project or phase and bring it to orderly end

These processes are overlapping and dependent on each other, which mean that one process produces the input for another process.

During the lifecycle of a dynamic virtual organization, similar processes exist. Some of the identified processes may be conducted in the BE, some in a VO. It seems reasonable that initialising and planning processes belong to the $\mathrm{BE}$. Initialising process would in the VO-concept be something more than just initialising for a project. This process might even be the core process of the BE. Initialising could include preparations for customer order, and the order itself would 
then trigger planning the process that is required to fulfil that specific customer need. Planning also includes set-up of the monitoring and management structures and it launches the executing and control processes. The closing of a VO is something more than just contract close-out and administrative closure. Further, part of the closing job continues surely in the BE and not all takes place during the VO.

Thus, even though the processes that are originally defined for projects can be found in VOs, rethinking is needed. The BE and VO concepts have different characteristics compared to traditional project networks (or CNOs). This implies that also the transition between these two concepts (from a BE into a VO) may need rethinking concerning the control processes.

\subsection{Recent European Research Projects and VOM}

As mentioned earlier, the approaches towards VOM in European projects were studied in the VOSTER project. In most of the analysed projects, the focus is on issues supporting the creation and management (frameworks, infrastructure, modelling, etc) of VOs rather than on management and management actions. However, in some of the reported projects (Camarinha-Matos et al., 2005), the management of VOs, and also the coordination and management issues, are addressed. For instance, the following relevant topics were addressed in these projects: inter-enterprise coordination, distributed engineering, scheduling in distributed (industrial) environment, cooperation planning in networked environment, monitoring in distributed environment and performance measurement, information and knowledge management, horizontal ICT infra and software tools.

Also organizational and social issues, including the creation and maintenance of trust, are considered in VO research. Trust can be seen as a success factor for cooperation, but trust as such does not make the operations less vulnerable. Justified trust is based on knowing the risk level. In VOs trust contributes to the efficiency of cooperation.

(Rezgui et al., 2005) consider organizations consisting of several interrelated elements, - strategy, staff, shared values, systems, skills, style and structure (The "seven S" model). Changes to any one element will have effects on the others. This can be seen as a socio-organizational equation, which must be balanced. The elements are expected to operate in harmony together for the organization to operate effectively. These issues must be taken into account also in VOM.

\section{VO CONTINGENCY FACTORS \& VO MANAGEMENT}

\subsection{Characterizing VOs}

There are some approaches to describe different characteristics of networks and virtual organizations. The Globeman 21 approach (Pedersen et al., 1999) identifies two kinds of descriptive parameters:

- situational factors: these are conditions coming from the environment (lead time requirements, types of needed competencies, ...); that is, factors which cannot be changed or selected. 
- design parameters: these are selected parameters (rules for the management, for exposure of competencies, legal aspects...). Thus there is not only one possible VO solution.

In VERAM (Virtual Enterprise Reference Architecture and Methodology) the situational factors and design parameters are called contingency factors (Zwegers et al. 2003). They are factors to be analyzed when designing a network or a VO.

\subsection{Feedback loop from VO to BE design parameters}

A VO is usually based on a Breeding Environment (network), even if the level of preparation may vary. Thus the features of the $\mathrm{BE}$ behind are situational factors for the VO.

On the other hand, the experience gained in VOs gives information to the BE. The VO experience may affect the BE design parameters and be useful in the evolving process of the BE (Figure 2). Currently this feedback loop is usually missing or weak.

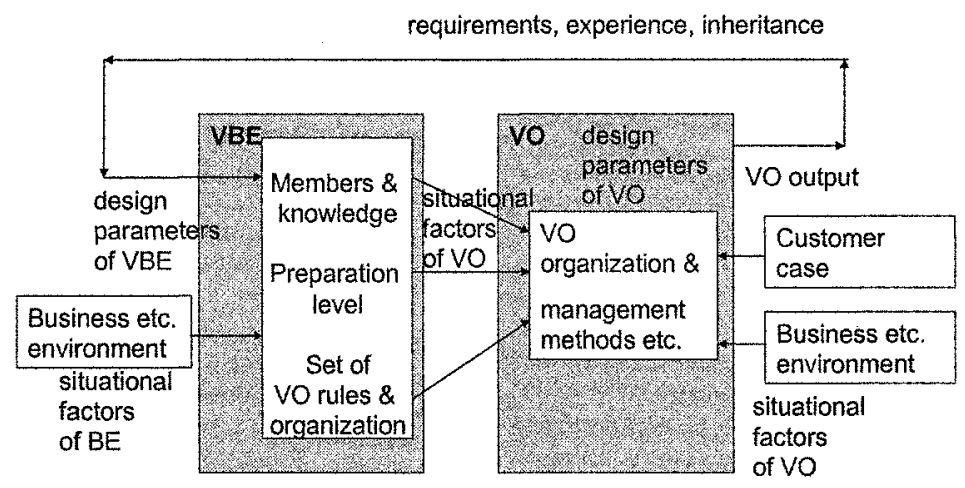

Figure 2. Feedback from VO output to BE design

\subsection{Review of VO topology and coordination}

\subsection{Topology classification}

The network or VO characterization applied mostly in the previous research is the topology classification. The topology is here understood as a structure describing all the different relationships between the partners (nodes of network), including information, material, monetary and control flows, responsibilities and power relationships. All the different flows do not always have the same routes and directions.

In CE-NET (Katzy \& Löh 2003) and VOSTER (Katzy et al., 2005) projects, where experience and knowledge of VO research and development projects were summarized, the following topologies could be identified (Figure 3):

- supply-chain topology; interaction of partners follows mainly a chain, links are in a tiered structure with each partner relating to its upper and lower neighbours. 
- star topology, or hub and spoke -topology, with one central partner (main contractor). Links are arranged predominantly star-like between a central partner and the other organisational entities.

- peer-to-peer topology; interaction between all nodes without hierarchy.

Typically each reviewed research project in VOSTER used one of these categories and most of the developed solutions made an assumption of a specific topology (Katzy et al., 2005).

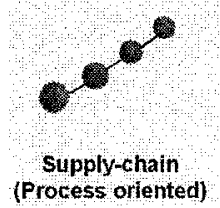

(Process onfented)

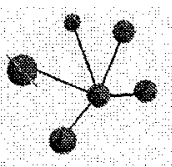

Hub and Spoke (Main contractor)

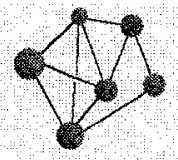

Peer-to-peer (Project oriented)

Figure 3. Topologies for Virtual Enterprises (Katzy et al., 2005).

The topologies can be applied both for BE (network) and VO. If the BE/VO processes are divided into operational processes and management processes, the following topologies are derived:

- $\mathrm{BE} /$ network operational topology and $\mathrm{BE} /$ network management topology

- VO operational topology and VO management topology.

The VO operational topology describes the physical and information flows needed for the production of the VO product (or service or value), and the VO management topology describes the information \& control flows of guiding the VO to its objective. Monetary flows can be seen as part of both processes.

The topologies are not necessarily the same for different processes or for a BE and a VO created from it. For example, even if the management topology is a star, there may be peer-to-peer processes at the operational level. A network with peerto-peer management may e.g. create a VO with star management topology.

From the VO management point of view the most significant topology is the VO management topology. Using the terminology above the topology is a design parameter of a VO, a feature that can be selected. On the other hand, there may be strong reasons (situational factors) why a certain topology is used and the selection is not totally free.

\subsubsection{Examples of topologies in manufacturing industry}

Henderson and Clark (1990) assume that the knowledge and information processing structure of organisations mirror the structure of the product that they manufacture. This assumption implies that the end product or purpose of the VO should be considered, when defining the structure and topology for the VO.

In recent research, the star VO topology has been identified in the field of oneof-a-kind manufacturing (GLOBEMEN, product-centric networks, Karvonen et al., 2002). When the products are extensive, complex systems, one of the partners typically has the responsibility of the product towards the customer. In the CE-NET study (Katzy \& Löh 2003) star-type VOs are mentioned to appear e.g. in construction industry (also one-of-a-kind). A study from Northern Germany has identified this type "General Virtual Contractor" (Hausner et al., 2003) in the the 
construction industry and large equipment manufacturing, but also in automotive and telecommunication industry. The supply-chain topology is often used for mass type production. Even if many networks or VOs operate in peer-to-peer structure, there are not as visible practical examples of VOs with peer-to-peer management topology. However, future organizations may be able to operate also without any centralized management, for example supported by pre-defined rules or agent technologies. This may mean that the responsibility towards the customer also becomes distributed.

\subsubsection{Structural holes and VOs aiming at innovation}

Several researchers interpret positive network structures and relations as social capital. Coleman (1988 \& 1990) and Burt (2004) take different viewpoints to social capital regarding networks. Coleman sees that cohesion in a network with numerous, and probably redundant ties between actors, yields social capital. The communication between the actors is effective, and trust and shared norms are strong. Burt considers, that an intermediary position between actors, which are away from each other, creates the best social value to the intermediary due to the rich information it receives and due to its control advantages.

In creating something new (R\&D and innovation VOs), effective VO topology may be different from an effective VO that produces more standardised outcome. Ahuja (2000) e.g. discusses the implications to innovation output by studying organisation's direct ties, indirect ties and structural holes. Figure 4 (modified from Ahuja, 2000, p. 428) illustrates these concepts.

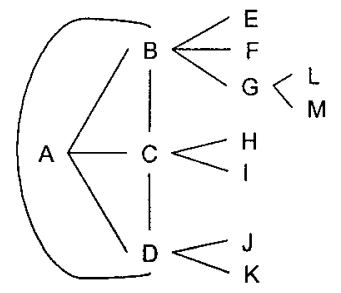

Figure 4. An example VO topology (Modified from Ahuja, 2000)

In Figure 4 organisations $\mathrm{A}, \mathrm{B}, \mathrm{C}$ and $\mathrm{D}$ all have direct ties between each other. They create a closed network with no structural holes from A's perspective. Organisation $B$ has direct ties to $\mathrm{E}, \mathrm{F}$ and $\mathrm{G}$, which further have ties to $\mathrm{L}$ and $\mathrm{M}$. These two latter ties are from B's perspective indirect. There are also structural holes (unconnected partners) between e.g. E, F and G.

The direct ties can provide knowledge sharing, complementary and scale, but having direct ties may add costs if maintaining the tie is costly. Indirect ties can, without significant costs, also provide benefits, like knowledge propagation. Structural holes then, as discussed earlier, and as Burt claims, enrich the information that an intermediary node in the network gains (e.g. organisation B may receive rich information from partners $\mathrm{E}, \mathrm{F}$ and $\mathrm{G}$ ).

Many researchers have studied the implications of these so called structural holes for the innovativeness (e.g. Ahuja, 2000; Burt, 2004). The results are not 
straightforward. The business context (e.g. matured - immature) seems to effect the preferable structure. The main finding is that the context in which the VO operates and the desired outcome of the VO should be considered when designing the VO structure, and that in some cases missing links may even be preferable. On the other hand, VOs with structural holes may be more vulnerable to opportunism and the extension of trust along the indirect ties is weaker.

According to the definitions, a VO is a temporary structure built from an existing $\mathrm{BE}$ (network). Additional consideration should be needed about the benefits or disadvantages of the crosswise combinations:

- creating a VO without structural holes from a BE with structural holes. In some cases this could support innovation, especially new ways of combining knowledge. A potential drawback is too low trust in the starting phase.

- creating a VO with structural holes from a BE without structural holes. Fewer links may, in some cases, be more effective, and the BE with the links creates a basis for trust.

\subsubsection{VO coordination}

The selection between star and supply chain VO management may depend on the VO operational topology, but the selection between peer-to-peer and the other topologies depends on the need for coordination. As the peer-to-peer management form has no central coordination, the VO coordination intensity can be considered as a key design factor for VO management.

Malone, \& Crowston (1994) define coordination: "Coordination is managing dependencies between activities."

A VO has a specific task and goal and a distributed organization to achieve it. VO coordination then means management of the dependencies of partners' activities in order to achieve the goal of the VO. A conclusion could be, that if there are no dependencies, there is no need for coordination, and, if there are strong dependencies, intensive coordination is needed. Dependencies may come from different sources: the VO objective or product type (an integrated package, where parts should fit together), the process type (input-output relationships) and resource allocations and scheduling.

The importance of the coordination also depends on the risk or consequences of not achieving the VO objective, and the model of risk sharing. If there are no losses in case of failure of the VO, it is not cost-effective to invest in coordination. If there is high risk of not achieving the goal with self-acting methodology, coordination is more important. On the other hand, if each partner only needs to tolerate its own risk and their risks do not depend on the other partners, coordination is less important.

It can be concluded that although the VO coordination intensity is a VO design parameter, it is determined based on two factors:

- the level of dependencies (partly designed, but partly situational)

- the risk involved in the VO objective (mostly a situational factor).

Partly the dependencies can be affected by the VO design, but the BE behind and the VO objective or product itself cause important restrictions on the design. As the involved risk highly depends on the VO objective, it can be concluded that the type 
of the VO objective /product/ service often determine the VO design parameters, including the management models and methods.

\subsection{From VO contingency factors to VO management approaches}

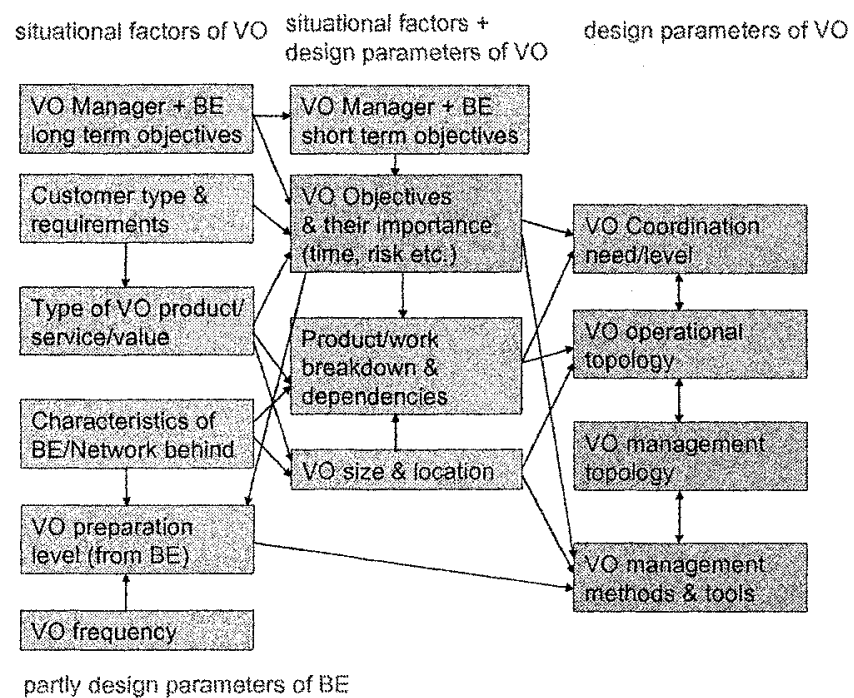

Figure 5. First map of VO contingency factors.

Figure 5 presents a map of VO contingency factors (situational factors and design parameters) relevant to VO management. The arrows between the entities present the influences between them. The elements on the left hand side mainly present parameters which are situational factors, the ones in the middle are partly situational factors (as the VO Objectives) and partly design parameters, and the ones on the right are VO design parameters. The aim is to identify the decisive entities and characteristics (situational factors) affecting recommendable VO methods.

The characteristics of Figure 5 were preliminarily analysed in 11 ECOLEAD VO scenarios/ cases with different types of products, sizes, locations, frequencies and operational topologies. For most of the cases the preparation level in the network/BE was considered low. Even if the products were different, all VO cases identified strong dependencies between the partners. Mostly this lead to high coordination intensity. The definition of used VO management methods and tools proved to be difficult in some cases; following a VO plan and reacting on exceptions were the most common methods. Measuring partners was described in some of the scenarios, but no well-defined VO management mechanisms / rules were defined.

Based on the analysis of scenarios some VO management approaches have been described for different combinations of VO objective \& dependencies \& risks in

Table 1. The different approaches partly overlap. To go further, proposals for VO management methods and mechanisms for different management approaches are needed. 
Table 1. First VO management approaches

\begin{tabular}{|c|c|c|}
\hline Approach & Application area & $\begin{array}{l}\text { Focus/ methods of } \\
\text { management }\end{array}$ \\
\hline $\begin{array}{l}\text { Project } \\
\text { management - } \\
\text { constrained } \\
\text { approach }\end{array}$ & $\begin{array}{l}\text { A specific task, a defined } \\
\text { goal. } \\
\text { Constrains with outcome, } \\
\text { costs \& schedule, high/ } \\
\text { medium risks, considerable } \\
\text { interdependencies of } \\
\text { tasks/operations (capital } \\
\text { projects), possibly strong } \\
\text { technical dependencies (SW } \\
\text { integration, capital projects) }\end{array}$ & $\begin{array}{l}\text { Effective/ medium operational/ } \\
\text { technical coordination } \\
\text { Planning, allocation of } \\
\text { resources, following a plan, } \\
\text { monitoring \& real time progress } \\
\text { measurement, reactive \& } \\
\text { proactive, often focus on } \\
\text { interfaces and dependencies. } \\
\text { (Monitoring of results/ } \\
\text { activities/ inputs) } \\
\text { Fast, emerging VOs with } \\
\text { standard detailed preplans/ } \\
\text { stand-by state. } \\
\text { Configurable / tailored plans } \\
\text { and one-of-a-kind VOs. }\end{array}$ \\
\hline $\begin{array}{l}\text { Supply Chain } \\
\text { Management } \\
\text { approach }\end{array}$ & $\begin{array}{l}\text { Supply chains, longer } \\
\text { duration, no "final" plans, ... }\end{array}$ & $\begin{array}{l}\text { Forecasting, allocation of } \\
\text { resources, planning, monitoring, } \\
\text { reallocation ...? }\end{array}$ \\
\hline $\begin{array}{l}\text { "Encouragement } \\
\text { approach" }\end{array}$ & $\begin{array}{l}\text { Abstract objective/ } \\
\text { changing objective/ not } \\
\text { constrained objective, first } \\
\text { phases of innovation } \\
\text { (invention), research, } \\
\text { business development. }\end{array}$ & $\begin{array}{l}\text { Clarification of objective, } \\
\text { building of common visions. } \\
\text { Management of scope \& } \\
\text { motivation, measuring } \\
\text { motivation \& performance? } \\
\text { rules for knowledge ownership } \\
\text { \& utilization }\end{array}$ \\
\hline $\begin{array}{l}\text { "Self-organizing - } \\
\text { internalized } \\
\text { common } \\
\text { objective" }\end{array}$ & $\begin{array}{l}\text { Self-willing - all the } \\
\text { partners have internalized } \\
\text { the objectives -the } \\
\text { objectives of partners } \\
\text { support each other, no } \\
\text { conflicts }\end{array}$ & $\begin{array}{l}\text { No coordination - management } \\
\text { of motivation \& result, } \\
\text { integration may be needed, } \\
\text { rules for sharing of results, } \\
\text { risks and knowledge are } \\
\text { needed. }\end{array}$ \\
\hline $\begin{array}{l}\text { "Automatic } \\
\text { control of VO" }\end{array}$ & $\begin{array}{l}\text { Partners with no conflicting } \\
\text { objectives/ predefined } \\
\text { solutions, give decision } \\
\text { power to the automated } \\
\text { system. }\end{array}$ & $\begin{array}{l}\text { Automated/semi-automated } \\
\text { follow-up of VO plan, } \\
\text { (semi)automatic negotiation and } \\
\text { decision making, no conflicts/ } \\
\text { automatic resolution, agent } \\
\text { systems? }\end{array}$ \\
\hline
\end{tabular}




\section{CONCLUSION}

\subsection{Challenges for further work}

To efficiently manage virtual organizations, a broad scope is necessary, which also can be seen in the definition of VO Management, presented in this paper. The main challenges in the management come from the temporary nature of a VO and the distribution of operations to several organizations. In addition, the VO is aimed to respond to fast changes in its environment, i.e. a dynamic management is needed, which also may include restructuring of the management approach or even the VO configuration.

The required dynamic management implies that needs of management actions are identified in real time. Consequently, an efficient performance measurement system should also be in place to give reliable, real-time indicators about the performance of the VO. The basic challenge for the work then becomes to develop real-time performance measurement based management approaches fulfilling the requirements and features described in this paper.

\subsection{Acknowledgments}

The paper is mainly based on work performed in the Integrated project ECOLEAD funded by the European Community under the Framework programme 6 (IP 506958).

\section{REFERENCES}

1. Ahuja, Gautam. Collaboration Networks, Structural Holes, and Innovation: A Longitudal Study. Administrative Science Quarterly, 45 (2000), pp. 425-455.

2. Burt, Ronald. Structural Holes and Good Ideas. American Journal of Sociology, 2004, pp 349-399.

3. Camarinha-Matos, L.M. and Afsarmanesh H., 2003. Elements of a base VE infrastructure. J. Computers in Industry, Vol. 51, No. 2, 139-163, 2003.

4. Camarinha-Matos, L., Afsarmanesh, H., Ollus, M. (eds.), 2005. Virtual organizations. Systems and Practices, Springer-Verlag. 2005.

5. Coleman, James S. Social capital in the creation of human capital. American Journal of Sociology, 1988, pp 95-120.

6. Coleman, James S., 1990. Foundations of Social Theory. Harvard University Press, Cambridge, MA. 1990

7. ECOLEAD D32.1 Challenges in Virtual Organisations Management. March 2005. www.ecolead.org.

8. GERAM, 1999. GERAM: Generalised Enterprise Reference Architecture and Methodology; Version 1.6.2; IFIP-IFAC Task Force, 1999

9. Hausner, U., Teichmann, K., Albers, S. \& Hussla, I. Management of Virtual Enterprises: Results from Case Studies in Northern Germany. In Weber, F., Pawar, K. \& Thoben, K.-D. (eds), Proceedings of the 9th International Conference on Concurrent Enterprising: "Enterprise Engineering in the Networked Economy", Espoo, Finiand, University of Nottingham, 2003;. 337-342.

10. Henderson Rebecca M., Clark Kim B. Architectural Innovation: The Reconfiguration of Existing product Technologies and the failure of Established Firms. Administrative Science Quarterly, Vol. 35, No. 1, Special Issue: Technology, Organisations, and Innovation. (Mar., 1990), pp 9-30. 
11. Karvonen, I. \& Jansson, K. \& Ollus, M. \& Hartel, I. \& Burger, G. \& Anastasiou, M. \& Välikangas, P. \& Mori, K. Inter-enterprise eCollaboration in Sales and Service of one-of-a-kind products. (In: Stanford-Smith, B. \& Chiozza, E. \& Edin, M. (Ed.), 2002). Challenges and Achievements in Ebusiness and E-work, IOS Press / Ohmsha, Berlin, Germany, 2002; 1388-1395.

12. Katzy, B. \& Löh, H. Virtual Enterprise Research State of the Art and Ways Forward. In Weber, F., Pawar, K. \& Thoben, K.-D. (eds), Proceedings of the 9th International Conference on Concurrent Enterprising: "Enterprise Engineering in the Networked Economy", Espoo, Finland , University of Nottingham, 2003; 343-353.

13. Katzy, B., Zhang, C. \& Lơh, H. Reference models for Virtual organisations, in Camarinha-Matos, L., Afsarmanesh, H., Ollus, M. (eds.), Virtual organizations. Systems and Practices, SpringerVerlag. 2005; 45-58.

14. Kürümlüoglu M., Nøstdal R., Karvonen, I. Base concepts, in Camarinha-Matos, L., Afsarmanesh, H., Ollus, M. (eds.), Virtual organizations. Systems and Practices, Springer-Verlag (2005), pp.11-28.

15. Malone, T.W., Crowstron, K. The interdisciplinary Study of Coordination. ACM Computing Surveys, 1994 (March), 26 (1), 87-119.

16. Pedersen, J.D., Tolle, M. Vesterager, J. Final report on Models. Deliverable 1.3 of Esprit 26509 Globeman 21 project. 1999

17. PMBOK, 1996. A Guide to the Project Management Body of Knowledge. Project Management Institute Standards Committee. 1996.

18. Rezgui, Y., Olphert W. and Damodaran L., 2005. Socio-organizational issues, in Camarinha-Matos, L., Afsarmanesh, H., Ollus, M. (eds.), Virtual organizations. Systems and Practices, SpringerVerlag (2005), pp. 187-198.

19. VOSTER: http://voster.vtt.fi/

20. Zwegers, A., Tolle, M, Vesterager J. VERAM: Virtual Enterprise Reference Architecture and Methodology., in Karvonen et al. Global Engineering and Manufacturing in Enterprise Networks (GLOBEMEN), VTT Symposium 224, 2003, p. 17-38. 